\title{
Malaysian ESL Teachers' Perception towards CEFR-Aligned Textbooks
}

\author{
Mohamad Lukman Al Hadi, Parilah Mohd Shah
}

\begin{abstract}
The implementation of CEFR in Malaysia begins in 2013, causing the Education reformation after the establishment of the English Language Standards and Quality Council (ELSQC). Since then, the English curriculum has evolved to be in-line with the CEFR Frameworks, including the transformation in syllabus and instructional materials. In 2017, the Ministry of Education introduced imported CEFR-aligned textbook to replace the local-based textbook beginning in Year One of local primary schools. Although the implementation caused heated arguments among stakeholders, these CEFR-alignedEnglish textbooks continued to be used until recently. 'Supermind' and 'Get Smart Plus' are imported English textbooks to be used in the English classrooms as the main textbook. Many researchers had conducted a study to evaluate the potentials of these textbooks. However, the study from teachers' point of view has yet to be done. Thus, this study aimed to seek ESL teachers' perceptions towards the use of imported CEFR-aligned textbooks in local primary schools. A total of 100 English teachers from rural and urban schools participated in this study. The data were collected through a questionnaire survey. The collected data was analysed by using descriptive and inferential statistics test via SPSS software. Thefindings discovered that the teachers have positive perceptions towards the use of these textbooks in the classroom. Apart from that, the difference in teachers' perception from different school background also are not significant. The study also revealed that teachers' experiences in teaching CEFR-aligned curriculum also did not affect their perceptions towards these textbooks.
\end{abstract}

Index Terms-CEFR-aligned textbooks, Evaluation, Malaysian Education Reform, Perceptions.

\section{INTRODUCTION}

\section{A. Common European Framework of References for Languages (CEFR)}

In 2001, Council of Europe introduced the Common European Framework of Reference for Languages or known as CEFR which is a framework with standardised guidelines on how learners should learn the languages according to their level of proficiency.Mohamad Uri and Abd Aziz [16] advocate that CEFR is a framework that clearly describes the requirements of language learners to accomplish to communicate in English and a basis of sound for mutual recognition of language qualifications. CEFR is beneficial to all level of people such as learners, teachers, policymakers, course designers, educational authorities, and other stakeholders as it providesthe utilisation of reference

Mohamad Lukman Al Hadi, SK Ladang Gajah Mati, Malaysia.

Parilah Mohd Shah (Associate Professor Dr.) National University of Malaysia, document to develop language curriculum, syllabus, courses, materials andto evaluate the learning outcomes.

Later, Malaysia implemented CEFR in lines with the Cambridge-level English as part of education reformation in the English curriculum in 2013 after the establishment of English Language Standards and Quality Council or known as ELSQC [16]. The council aims to assist the Ministry of Education to enhance English proficiency levels among Malaysia students. There are six language proficiency levels in CEFR which are from A1, A2, B1, B2, C1 and C2. The framework began with A1 level that represents the learners who acquired the most basic and lowest proficiency of the language until C2 levels that represent the advanced and highly proficient learners. The proficiency in each level was thoroughly elaborated with 'can-do' statements. The framework focused on the development of language learners by stating the learning objectives of the primary language skills where they should complete in every learning stage [15].

\section{B. Imported CEFR-Aligned Textbooks Replacing Local Based Textbooks}

In order to cater to the standard of CEFR-aligned curriculum, Ministry of Education in Malaysia announced the use of imported textbooks in English language classes at public schools aiming to achieve the national education goal which is to enhance the standard of English in schools so that it would be in line with the CEFR-aligned curriculum. The previous local English textbooks were replaced with the imported textbooks, namely Super minds for Year 1 and Year 2 since 2017 and 2018. At the beginning of 2019, Get Smart Plus 3 was introduced as the primary textbook for Year 3 and followed by 'Get Smart Plus 4' in the year of 2020.

Diniah [19] defines textbook as a medium used in a language teaching and learning process and teachers and students need to have them. The textbook is a vital learning material as it is not only serving content and knowledge to the learners, but it also provides guidelines and framework for teachers to plan their lesson. A textbook in Malaysia education system always undergone evolution parallel with the revolution of the educational curriculum.

\section{Problem Statement}

The imported textbooks are believed to be adequate with content that aligned with the CEFR-aligned curriculum. Regardless, the perks of having imported textbook as a replacement to the local textbooks been discussed thoroughly by the experts, the arguments of the suitability of the imported textbooks in the local context were still heated among teachers. The suitability of the imported textbook 
contents and its' cultural elements in it could cause quite a challenge to the teachers, especially in rural schools, to carry out the lesson successfully.

The evaluation of these textbooks had been done by the Textbook Division of Ministry of Education, yet it is also vital for teachers to evaluate the textbooks as they will use the textbooks as their primary source in teaching the language. The textbook evaluation would be prerequisite for teaching and learning as teachers need to adapt the content of the textbooks to suit their learners' proficiency level. Roberts, Abdul Aziz and Mohd Matore [4] stated that textbook evaluation could do a favour for teachers to design learning materials to suit the learners' interest and preferences better and also customise the deficiencies of the textbook.

There are multiple kinds of research and studies been conducted to evaluate the implementation of the CEFR-aligned curriculum. However, the study on the perceptions towards the use of these imported textbooks are still at the surface level. Therefore, this study aims to explore teachers' attitude and perceptions of imported English textbooks among primary schools in Malaysia and its' relating factors that influenced their perceptions.

\section{Research Questions}

\section{LITERATURE REVIEW}

\section{A. The Roles and Limitations of Textbooks in ESL Classroom}

Textbooks are considered as the most vital material to be used by the teachers and learners in the ESL classroom. Srakang [10] stated that textbooks play an essential role in all types of educational institutions and there are several numbers of debates in the roles of the textbooks in ESL classrooms in terms of potential and limitations.

Mustapha as cited in Johar andAbdul Aziz [15] stated that textbooks play an essential function in language teaching as it is the first conceptualisation of the syllabus. The utilisation of the textbook in the classroom helps teachers to conduct the teaching and learning process properly and systematically as textbook provides a guideline for teachers to teach the language. The textbook is a beneficial tool for ELT as it provides a framework, methodology and sources of ideas for them [13].

Textbooks also could be a great time saver and planner for teachers as it completed with content and activities suggested to be used in the classroom. Srakang [10] pointed out that textbooks reduce time in preparing the materials so teachers can utilise more hours to teaching. Textbooks are designed to provide cohesive language teaching and learning by supplying direction support and suggested language-based activities for the classroom practice [9]. Thus, a good textbook that completed with a good suggestion of activities and direction will be able to assist teachers in creating a successful language teaching and learning. In addition, textbooks also could help inexperienced teachers in lesson planning and gaining confidence with their lesson. Srakang [9] also pointed out that the textbook can train inexperienced teachers to be more confident in lesson planning and teaching in the classroom.

Rahimi and Hassani [13] pointed out that there are potential disadvantages of using textbooks. Despite its positive values, textbooks can bring adverse effects to the successfulness of ELT. Swales as cited in Srakang [10] stated that educational failure could be the damage of heavy use of the textbooks. Richards [8] claimed that textbook might consist of inauthentic language, incomplete content, deskilled teachers and also may not suit learners' needs. Besides, the context in the textbook also may not culturally sufficient to the learners. Aliabakri [11] in his study of Iranian ELT textbooks in high school level revealed that the inclusion of cultural elements in the books was underrepresented later he suggested that the textbook did not correctly assist the learners in reinforcing their intercultural communication and understanding. Besides, Ur as cited in Srakang [10] asserts that textbooks did not sufficiently cater to the learners' needs. Textbooks may not adequate with all the learners' needs that it can cause major failure to the learners' achievement. The researcher [10] also stated that textbooks are usually failed to provide a wide range of levels ability and also lacking in knowledge of learning styles and strategies.

\section{B. Importance of Textbook Evaluation}

The perfect textbooks do not exist, but the best textbooks for teachers and learners do exist [13]. The best textbooks should cater to the learners' needs, interests and provide multiple opportunities to the learners to be independent learners. Thus, in order to decide the best textbooks as teaching and learning materials, textbook evaluations should be carried out by the higher authority or among teachers.

Hutchinson [13] defined evaluation as the matters of decision the suitability of something for a particular goal. In terms of language teaching, evaluation is a process of decision making whether the materials, in this case, textbook, able to fit into the English curriculum to achieve the goal of education policy. Richards [8] suggested that materials evaluation can be done by the outside observer to see the effectiveness of the textbooks, a group of teachers may write reviews or reports regarding the textbook or students can give a review to share their experience working with the textbooks. Obaid [18] stated that text evaluation is done to identify any potentials and limitations of the textbooks and ease the textbook selection process by minimising the limitations and maximising the strengths of the textbooks.

\section{Past Studies on Textbook Evaluation}

In Malaysia, the textbook evaluation was thoroughly scrutinised by the Textbook Division of Ministry of Education before it was passed down to schools. Nevertheless, textbook evaluation should be done by the teachers themselves to get an in-depth understanding of the textbook used. Thus, researchers carried out several studies on the evaluation of the textbook in Malaysia school context.

Kalajahi and Mukundan [9] carried out a study on the Malaysian English textbooks evaluation with the aim to evaluate the suitability of the textbooks to the learners and the capability to assist teachers in achieving pedagogical goals of the new curriculum. The study was done through a checklist to collect data from 944 English teachers that explicitly teach primary and secondary students. The results between primary and secondary teachers slightly different from one another. The researches stated that the primary school teachers 
advocated that the textbooks are highly useful to the students while the secondary school teachers stated that the book was moderately useful.

\section{Concept of Perceptions}

Perceptions of the teachers are like a personal belief held by them regarding the curriculum, their teaching content, their responsibility as well as their beliefs towards the students and classroom [15]. Roberts, Abdul Aziz and Mohd Matore [4] also described perceptions as a process of organising and interpreting their impression to make meaning to their environment. Perceptions are like a personal impression or opinions of some issues that are interpreted by the receptor.

In the teaching profession, it is crucial to take into account teachers' perceptions. Donaghue as cited in Johar and Abdul Aziz [15] pointed out that perceptions of teachers began with teachers' experiences and personality that help them in the teaching profession. Kurniawati as cited in Srakang [10] indicates that teachers' beliefs are tools to understand their practices and values of teaching. Teachers' perceptions could give a description of the reality in the classroom to the higher authority in order to enhance the quality of the teaching profession. According to Jia as cited in Srakang [10], it is believed that by exploring perceptions of teachers could help in obtaining a more profound understanding of their attitudes in the classrooms as well as to provide guidance in enhancing their practices.

\section{E. Past Studies on Teachers' Perceptions}

A study conducted by Roberts, Abdul Aziz and Mohd Matore [4] on Malaysian teachers' perceptions of the Cambridge English textbook. This study aimed to identify teachers' perceptions in using the evaluation checklist for the adaptation of the materials. The study was carried out to six teachers from Kuala Lumpur via online qualitative interview by using mobile instant messaging and coded through Nvivo version 12 . The results of the study revealed that the checklist has its strengths and weaknesses. The weakness of the checklist highlighted the need to improve the checklist and customised to suit the specific context.

Johar and Abdul Aziz [15] also carried out a study on teachers' perceptions on Using the Pulse 2 textbook to explore perceptions of teachers in using the textbook. This case study was conducted to five teachers who are teaching Form 1 and 2 in the secondary schools in Marang, Terengganu via interview. The findings reveal that there were mixed perceptions from the respondents as they perceived the aspects in the textbooks consists of both potentials and limitations. The respondents perceived negatively towards the cultural presentations in the textbook as the local cultural context was at the minimum level or almost none. Thus, the students find it challenging to learn the language as they could not relate the language to their context.

\section{Methodology}

\section{A. Research Design}

Quantitative research was used to collect data on Malaysian ESL teachers' perceptions towards the use of CEFR-aligned textbooks. Hence, thisresearch employed a survey research design to collect the data from the teachers.

\section{B. Participants and Setting}

This study aimed to identify the perceptions of primary schools' English teachers who have been teaching the English Language for Year 1, 2, 3 and 4. A total number of 116 English teachers who teach in the local primary schools participated in this study. The participants of this study were chosen randomly through simple random sampling.

Sharma [6] stated that probability sampling or also known as random sampling is a sampling scheme in which the choice probability for each person is the same. Under random sampling, simple random sampling is chosen for this study. In simple random sampling, each individual in the population has an equal opportunity of being chosen as a subject. Simple random sampling is easy to gather the samples and also considered as a fair process of choosing the sample from the given population. Sharma [6] also points out that it is vital to have an unbiased random selection and a representative of the samples to conclude the findings of a study. In conclusion, with regards the factors and the pros of simple random sampling technique, it was appropriate for this study to apply simple random sampling method to select the samples from a bigger population of teachers to be the subject for this study.

\section{Instrument}

A questionnaire was used as an instrument for this study to collect the data from the participants. This study adapted a questionnaire survey from Srakang [10] who studied teachers' perceptions towards using English textbook in Thailand. The questionnaire consists of close-ended questions that have been divided into three sections namely;a) demographic background b) evaluation on CEFR-aligned textbooks and c) role of the textbooks in the ESL classrooms. Section B and C consists of 35 items that employed 5-Likert scales to determine the level of agreement of the participants in which score 5 represents 'strongly agree', score 4 shows 'agree' and score 3 indicated that the teachers are being neutral while score 2 and 1 indicated that they are being 'disagree' and 'strongly disagree'.

\section{Procedures}

The study involved a few procedures in the data collection. Firstly, the adapted questionnaire was supervised by the expert in research to check its' reliability and validity of the items. After the consultation, the questionnaire was created by using Google Form instead of paper. The rationale of using Google Form was to ease the data collection from the participants. Once the link for the questionnaire was ready, the link was sent via instant group messaging app known as Whatsapp group. The consent to conduct the study will be obtained from the admin of the Whatsapp groups. The group consists of English teachers who teach in primary schools in Malaysia. The teachers will be instructed to answer the following questionnaire by clicking the levels of agreement based on the statements. After that, the teachers are required to click on Submit in order for the responses to be recorded. The recorded responses were analysed by using the Statistical Package for the Social Sciences version 25 (SPSS v.25) system. 


\section{E. Data Analysis}

This study was using two types of statistics which were descriptive and inferential statistics. The first part of the data analysis used descriptive statistics.Chua [20] defines descriptive statistics as a statistic to describe the characteristics of the variables by using mean, standard deviation, median, mode, Z-score and many more. Descriptive statistic functions as a description of the variables and to conclude the numerical data. However, the results of descriptive statistic cannot be generalised to the bigger population.

The first research question was analysed by using descriptive statistics in which the mean values were calculated. The mean values of interpreted for the adapted questionnaire were adopted from Srakang [10] are as follows:

TABLE1. THE AGREEMENT LEVEL OF INTERPRETED VALUE

\begin{tabular}{|c|c|}
\hline Interpreted Mean Value & Level of Agreement \\
\hline $4.50-5.00$ & Strongly agree \\
\hline $3.50-4.49$ & Agree \\
\hline $2.50-3.49$ & Neutral \\
\hline $1.50-2.49$ & Disagree \\
\hline $0.00-1.49$ & Strongly disagree \\
\hline
\end{tabular}

The second research question was analysed by using inferential statistic. According to Chua [20], one of the prerequisites to conduct inferential statistics tests is that the collected data must be normally distributed. The normality of the data can be determined by using Kolmogorov-Smirnov or Shapiro-Wilk test. If the collected data is normally distributed, Independent Sample T-test will be used to find the significant differences in perceptions of teachers in the rural and urban area. Hence, the independent sample T-test wasdone via the SPSS system.

\section{FINDINGS}

The findings of this study weredescribed to answer two research questions: a) what are teachers' perceptions of the use of CEFR-aligned textbooks b) Is there a significant difference between urban and rural schools with respect to their perceptions towards CEFR-aligned textbooks?

\section{A. Demographic Background}

The demographic background of the teachers was included in this study to have a better understanding of their choices. There are three aspects in this section, namely gender, number of years teaching CEFR-aligned curriculum and location of the school. From the finding, the total number of $91(78.4 \%)$ female teachers had answered the questionnaire and surpassing the numbers of male teachers which only 25 $(21.6 \%)$ teachers.

Next, the aspect of schools' location is very crucial in this study as it may be the factor that varies the perceptions of the teachers towards the use of the textbooks in the school. Hence, in this study the numbers of teachers who teach in urban school are equal to the number of teachers who teach in rural schools.

\section{B. What are Malaysian ESL Teachers' perceptions towards CEFR-aligned textbooks?}

There are 32 items in the second and third sections of the questionnaire. The data were tabulated and analysed by using descriptive analysis which is the mean.The mean of each statement was calculated and ranked to ease the data analysis by using Microsoft Excel software. The first five highest ranked statements for each section. were discussed in this study. The mean for the questionnaire was also calculated to obtain overall perceptions of the teachers towards the textbooks. The findings are shown in table 2 .

TABLE 2. THE MEAN OF TEACHERS' PERCEPTIONS TOWARDS CEFR-ALIGNED TEXTBOOKS.

\begin{tabular}{|c|c|c|c|}
\hline Item & Statements & $\bar{x}$ & $\begin{array}{c}\text { Level of } \\
\text { agreement }\end{array}$ \\
\hline \multicolumn{4}{|c|}{ Section B: The evaluation of CEFR-aligned textbooks } \\
\hline 1 & $\begin{array}{l}\text { The textbook comes } \\
\text { with audio CDs, } \\
\text { supplementary materials } \\
\text { and teacher's guide } \\
\text { book. }\end{array}$ & 4.42 & Agree \\
\hline 2 & $\begin{array}{l}\text { The layout and design } \\
\text { are attractive and easy to } \\
\text { read. }\end{array}$ & 4.19 & Agree \\
\hline 3 & $\begin{array}{l}\text { The subject and contents } \\
\text { of the textbooks are } \\
\text { relevant to the } \\
\text { CEFR-based } \\
\text { curriculum. }\end{array}$ & 4.19 & Agree \\
\hline 4 & $\begin{array}{l}\text { The instructions are } \\
\text { clearly stated. }\end{array}$ & 4.10 & Agree \\
\hline 5 & $\begin{array}{l}\text { There is an appropriate } \\
\text { balance of the four } \\
\text { language skills. }\end{array}$ & 3.99 & Agree \\
\hline 6 & $\begin{array}{l}\text { The price of the } \\
\text { textbook is affordable. }\end{array}$ & 3.12 & Neutral \\
\hline 7 & $\begin{array}{l}\text { The culture presented in } \\
\text { the textbook is } \\
\text { appropriate for } \\
\text { Malaysian context. }\end{array}$ & 3.11 & Neutral \\
\hline \multicolumn{4}{|c|}{ Section C: The role of textbooks. } \\
\hline 8 & $\begin{array}{l}\text { I made some adjustment } \\
\text { to the content of the } \\
\text { textbook to suit the } \\
\text { learners' context. }\end{array}$ & 4.27 & Agree \\
\hline 9 & $\begin{array}{l}\text { I fully understand the } \\
\text { content presented in the } \\
\text { textbooks. }\end{array}$ & 4.19 & Agree \\
\hline 10 & $\begin{array}{l}\text { The textbook serves as } \\
\text { the main syllabus of the } \\
\text { current curriculum. }\end{array}$ & 4.16 & Agree \\
\hline 11 & $\begin{array}{l}\text { The textbook helps me } \\
\text { in planning a daily } \\
\text { lesson }\end{array}$ & 4.13 & Agree \\
\hline 12 & $\begin{array}{l}\text { I fully understand the } \\
\text { cultural issues presented } \\
\text { in the textbooks. }\end{array}$ & 4.11 & Agree \\
\hline 13 & I teach exclusively from & 3.74 & Agree \\
\hline
\end{tabular}




\begin{tabular}{|c|l|l|l|}
\hline & the textbook. & & \\
\hline 14 & $\begin{array}{l}\text { I rely on the textbook } \\
\text { when I'm teaching. }\end{array}$ & 3.63 & Agree \\
\hline
\end{tabular}

Table 2 indicated the means for teachers' perceptions towards CEFR-aligned textbooks based on the statements in the questionnaire.The overall mean for the questionnaire is 3.90indicated that the teachers had agreed and feeling positive towards that use of CEFR-aligned textbooks and its' roles in the English language teaching.

Item 1: The textbook comes with audio CDs, supplementary materials and teacher's guide book.

The highest rank with the mean of 4.42 shows that the teachers have positive perceptions towards the package that the textbook has offered. The teachers agreed that the textbooks are completed with the supplementary materials, audio CDs and teachers' guide book.

Item 2: The layout and design are attractive and easy to read.

The second-highest rank with the mean of 4.19 is the perception towards the layout and the design of the textbook. The teachers agreed that the layout and design are attractive and easy to read.

Item 3: The subject and contents of the textbooks are relevant to the CEFR-based curriculum.

Another statement that also obtained same mean value of 4.19 is the subjects and contents of the textbooks are relevant to CEFR-aligned curriculum. The teachers see eye to eye that the textbooks are in line with the current Malaysian education curriculum.

Item 4: The instructions are clearly stated.

The perceptions towards the instruction used in the textbook came in the fourth rank with mean value of 4.10 . The teachers have agreed that the instructions in the textbook are clearly stated.

Item 5: There is an appropriate balance of the four language skills.

Lastly, the fifth-highest rank with the mean of 3.99 described that the teachers agreed that textbooks consist of appropriate balance of the four language skills.

Item 6: The price of the textbook is affordable.

The teachers were neither agree nor disagree with the culture presented in the textbook whether it is appropriate to the Malaysian context with the mean value of 3.11 .

Item 7: The culture presented in the textbook is appropriate for Malaysian context.

Another statement with the mean value of 3.12 is the price of the textbook. The teachers were feeling neutral with the price of the CEFR-aligned textbook.

Item 8: I made some adjustment to the content of the textbook to suit the learners' context.

The highest rank in section $\mathrm{C}$ with the mean of 4.27 shows that the teachers made some adjustment to the content of the textbooks to suit their learners' need.

Item 9:I fully understand the content presented in the textbooks.

The second-highest rank with the mean of 4.19 indicated that the teachers are fully understand the content presented in the textbooks. This indicated that the teachers are very familiar with these CEFR-aligned textbooks.
Item 10:The textbook serves as the main syllabus of the current curriculum.

The third-highest rank with the mean score of 4.16 shows that the teachers agreed that the textbooks serves as the main syllabus of the CEFR-aligned curriculum.

Item 11: The textbook helps me in planning a daily lesson

The fourth highest rank with the mean of 4.13 indicated that the teachers agreed that the CEFR-aligned textbook did help them in planning their daily lesson.

Item 12:I fully understand the cultural issues presented in the textbooks.

Lastly, the fifth-highest rank with the mean of 4.11 described that the teachers were fully understand the cultural issues presented in the textbooks.

Item 13: I teach exclusively from the textbook.

The lowest ranked statement with the mean score of 3.63 is the teachers agree that the teacher rely on the textbook when they teach.

Item 14: I rely on the textbook when I'm teaching.

The second lowest ranked with the mean score 3.74 was the teacher agreed that they teach exclusively from the textbook.

\section{Is there any significant difference between urban and} rural schools with respect to their perceptions of the textbook?

Independent sample T-test was used to answer the second research question as stated above. The findings are as follows.

TABLE 3. THE SSPS OUTPUT OF INDEPENDENCE SAMPLE T-TEST

\begin{tabular}{|c|c|c|c|c|}
\hline \multirow{3}{*}{ Mean } & \multicolumn{4}{|c|}{ T-test of equality of means } \\
\hline \multirow{3}{*}{} & $\mathrm{t}$ & $\mathrm{df}$ & $\begin{array}{c}\text { Sig. } \\
\text { (2-tailed) }\end{array}$ & $\begin{array}{c}\text { Mean } \\
\text { Differenece }\end{array}$ \\
\cline { 2 - 5 } & .127 & 114 & .899 & .013483 \\
\hline
\end{tabular}

According to table 7 , the significant value of the test (0.899) is bigger than $\mathrm{p}<0.05$. The outcome of the test indicated that the difference between urban and rural schools' teachers with respect to their perceptions towards CEFR-aligned textbook is not significant with $\mathrm{t}(114)=$ $0.127 ; \mathrm{p}<0.05$. Therefore, it is failed to reject the null hypothesis, which means there is a no significant difference in perceptions toward the CEFR-aligned textbook between urban and rural school teachers. However, the mean for rural school teachers (3.904) is slightly higher than the mean for urban school teachers (3.891). With the mean difference (0.135) in table 7 indicated that rural school teachers more positive towards the use of the CEFR-aligned textbooks as compared to the urban school teachers.

\section{Discussion}

Generally, the study found that the total mean of the questionnaire indicated that the teachers have positive perceptions of the textbook and its' role in the classroom. The first impression of the teachers towards the CEFR-aligned textbooks was positive as most teachers are agreed that the 
textbooks come with the supplementary materials. The first impression of the textbook is essential as it is prerequisite of choosing the excellent textbook. A textbook that is complete with the additional materials can reduce teachers' workload in preparing the materials for the lesson. A good textbook can aid teachers with its full activities and contents so the teachers do not have to prepare too many materials [10]. In addition, the previous studies stated that the textbooks could help teachers in planning the lesson and help teachers to reduce the time consumptions and the workloads.

The teachers are also positive with the layout and the design of the textbooks. The findings of the study by Kirkgoz as cited in Obaid [18] also found that the students preferred the textbook that was colourful, contains pictures with interesting characters, drawing and suits to their own level. Besides, the teachers were alsoperceived positively towards the subjects and contents of textbooks which related to CEFR-aligned curriculum. Richards [8] advocates that textbook consists of structure and syllabus in which a curriculum may have no impact without it. Next, the teachers have positive perceptions towards the instructions provided in the CEFR-aligned textbook. Clear and precise instructions help to ease the flow of the lesson. Also, the teachers agreed that CEFR-aligned textbooks are adequate with activities and practices that cover all four language skills.

However, the teachers were neither agree nor disagree with the statements that the cultural elements in the textbook are appropriate in Malaysia context. Since the 'Supermind' and 'Get Smart Plus' are the imported textbooks, the content in it may not be culturally appropriate to the Malaysian classroom context. Tok [7] points out that the problem of most textbooks is that they are culturally or socially biased. The teachers were also feeling neutral towards the price of the textbooks. The imported CEFR-aligned textbooks were given to the schools by the Ministry of Education as the main textbooks complete with the supplementary materials and teachers' guide books. Since the free textbook policy implemented in Malaysia for many years, the parents do not have to buy the textbooks for the children. Hence, the aspect of the textbooks' price in this study may not be relevant, resulting in such response in the finding.

In the second section, most of the teachers agreed that they made some adjustment to the content of the textbooks to suit leaners' context. Teachers know their pupils best that they understand their needs and preferred learning styles [18]. In order to do the adjustment, the teachers themselves need to understand the contents of the textbooks. This reflected on the second statement with the highest mean score indicated that teachers agreed that they were fully understand of the contents presented in the textbooks. The teachers are also agreed that the textbooks serve as the main syllabus of the current curriculum as the statement came in the third highest mean score. Textbooks are indeed essentials component of the curriculum as it provides a clear framework for teachers and students [18]. Tomlinson as cited in Srakang [10] stated that the textbook is a source of guidance and ideas for teachers on lesson planning. These potentials are reflected in the findings in which the fourth statement in the second section that obtains highest mean score indicated that teachers agreed that the textbooks help them in planning the lesson and provide them with adequate activities that it reduces their preparation load.

Lastly, the findings also found that there is no significant difference in the perceptions of rural and school teachers. The mean score between two different locations are almost similar. In fact, teachers who are from rural schools slightly more positive than the teachers from the urban schools. Normally, the schools in the rural area typically inadequate in term of infrastructure and the readiness of the learners towards learning English as compared to urban school, which affect the way of teachers use the textbooks in the classroom. However, the result shows differently. Based on the result, the teachers in rural schools are slightly more positive towards the textbooks as compared to teachers in an urban area. Further study should be conducted to find out the factors affecting their perceptions in these two schools.

\section{CONCLUSION}

In conclusion, the findings of this study indicated that the teachers have positive perceptions of the CEFR-aligned textbooks regardless of the limitations of the textbooks. They believe that textbooks can provide an ample amount of activities and practices that can maximise the language learning in the classroom. Besides, the teachers also acknowledge that the textbooks do help them in planning the lesson by making the process more manageable with the suggested activities and explicit instruction in the textbook. The contents of the textbooks are also in favour of the teachers as it provides adequate language skill practices that suit learners' need. This study also revealed that the schools' location does not have any impact the perceptions of the teachers towards the use of textbooks. Surprisingly, the teachers in rural school have more positive perceptions towards the textbooks as compared to the teachers in urban school even though they are at disadvantages in terms of infrastructure and resources.

Based on the study's findings, it is recommended for the teachers to utilise the CEFR-aligned textbooks fully and adapted it according to learners' proficiency level and needs. The teachers should not solely depend on the textbooks by thinking out of the boxes to maximise the language learning, especially in ESL classroom. This study was only carried out to seek perceptions towards the imported CEFR-aligned textbooks which are used by the primary school pupils. Therefore, the future study can focus on a bigger scope with a larger number of samples so that the validity and reliability of the study can be increased. Another method such as interview should be included in the future study so that the researcher can focus on the factors that may affect their perceptions.

\section{REFERENCES}

[1] E. Daniel, "The usefulness of qualitative and quantitative approaches and methods in researching problem-solving ability in Science education curriculum," Journal of Education and Practice, vol.7(15), 2016, pp.91-100.

[2] F. Ebrahimi and R. Sahragard, "Teachers' perceptions of the new English textbooks in Iranian Junior Highschools," The Journal of Asia TEFL, vol. 14(2), 2017, pp.355-363.

[3] F. F. Mohammad Din and H. Yamat, "Challenges faced by teachers in using Supermind Textbook," International Journal of Academic Research in Progressive Education and Development, vol.9(1), 2020, pp. 122-133. 
[4] F. Roberts, A. Abdul Aziz and M. E. E. Mohd Matore, "Malaysian teachers' perceptions on Cambridge English textbook evaluation checklist for materials adaptation: A preliminary study," International Journal of Advanced Science and Technology, vol.29(3), 2020, pp. 2020-2030.

[5] G.G. Jerald, and P. M. Shah, "The impact of CEFR-aligned curriculum in the teaching of ESL in Julau district: English teachers' perspectives," International Journal of Innovative Research and Creative Technology, vol.4(6), 2018, pp.121-125.

[6] G. Sharma, "Pros and cons of different sampling techniques," International Journal of Applied Research, vol.3 (7), 2017, pp. 749 -752 .

[7] H. Tok, "TEFL textbook evaluation: From teachers' perspectives," Educational Research and Review, vol.5(9), 2010, pp.508-517.

[8] J.C. Richards, Curriculum development in language teaching. Cambridge: Cambridge University Press, 2001.

[9] J. Mukundan, and S.A.R. Kalajahi,"Evaluation of Malaysia English language teaching textbooks," International Journal of Education and Literacy Studies, vol.1(1), 2013, 28-46.

[10] L, Srakang, 2013. “A study of teachers' perceptions towards using English textbooks: A case study of $10^{\text {th }}$ grade English teachers in Maha Sarakham Province," Master Dissertation, Srinakhawat University, Thailand, unpublished.

[11] M. Aliakbari and B. Jamalvandi, "Realisation of culture in English textbooks in Chinese High School level," Journal of Pan-Pacific Association of Applied Linguistics, vol.16(2), 2013, pp.89 - 101.

[12] M.K. Ngu and A. Abdul Aziz, 2019. "English language teachers' perceptions on the implementation of CEFR-aligned curriculum among primary schools in Malaysia," Proceedings of Seminar Wacana Pendidikan, 2019, pp. 212 -222.

[13] M. Rahimi and M. Hassani, "Attitude towards EFL textbooks as a predictor of attitude towards learning English as a foreign language," Procedia - Social and Behavioral Sciences, vol.31, 2012, pp.66-72.

[14] M.S. Rahman, 2016. "The advantages and disadvantages of using Qualitative and Quantitative approaches and methods in language "Test and Assessment" Research: A literature review," Journal of Education and Learning, vol.6(1), 2016, pp.102-112.

[15] N. A. Johar and A. Abdul Aziz. 2019. "Teachers' perceptions on using the Pulse 2 textbook," Journal of Educational Research and Indigenous Studies, vol.2(1), 2019, pp. 2-16.

[16] N. F. Mohamad Uri and M. S. Abd Aziz, 2018. "Implementation of CEFR in Malaysia: Teachers' awareness and the challenges," $3 L:$ The Southeast Asian Journal of English Language Studies, vol. 24(3), 2018, pp. $168-183$.

[17] P.P. James, and A. Abdul Aziz, "Perceptions and expectancies of Malaysian Students on cultural elements in foreign textbooks," International Journal of Academic Research in Bussiness and Social Sciences, vol.10(4), 2020, pp.214-213.

[18] R. Obaid, "An evaluation of the second intermediate Saudi English language textbook from teachers' point of view," Advances in Language and Literary Studies, vol.7(2), 2016 pp.231-248.

[19] S.N. Diniah, “Teachers' perceptions towards the use of English textbook in EFL classrooms: A descriptive study of EFL Teachers at One Islamic Senior High School in Cirebon," Journal of English and Education, vol.1(2), 2013, pp. 72-81.

[20] Y.P. Chua, 2012. Asas statistik penyelidikan. Kuala Lumpur: McGrawHill publications, 2012, pp.75-79.

Mohamad Lukman Al Hadiis a TESL major student in Masters of Education in TESL in National University of Malaysia, 43600 Bangi, Selangor, Malaysia. He graduated from Teachers' Training Institute of Penang Campus in 2015 with a Bachelor's Degree in TESL.He is currently teaching English language in SJKC Pay Chuin, Melaka from 2016 until 2019. In 2020, he transferred to rural school inDungun, Terengganu, Malaysia. He has achieved a bronze awards in International Invention \& Innovative Competition (InIIC Series 2/2019) under 'Higher Institution Students (Social Science)' category.

Parilah Mohd Shah is an Associate Professor at Faculty of Education in National University of Malaysia, 43600 Bangi, Selangor, Malaysia. She received her M.A. and Ph.D. from University of Connecticut, USA. Her research interest is second language acquisition, teaching methodology, bilingual-bicultural education as well as learning challenges and need among second language learners. She had presented papers at national and international levels. Besides that, she also had published several papers in areas related to second language acquisition and reading strategies. 